\title{
STUDY OF FINGERPRINTS PATTERN IN BREAST CANCER PATIENTS INSHARKIA GOVERNORATE, A CASE -CONTROL RETROSPECTIVE CLINICAL STUDY.
}

\section{Alaa Ahmed Haggag, Alaa Mohamed Ibrahim Khalil, Eman Salah-eldin Elzahed, Mohamed Ibrahim Abdelhamid ,2017.}

General Surgery Department

\section{ABSTRACT}

Background :Worldwide, breast cancer is the most frequently diagnosed life-threatening cancer in women. In less-developed countries, it is the leading cause of cancer death in women; in developed countries. Breast cancer is one of the most extensively studied cancers and its genetic basis is well established.Dermatoglyphic traits are formed under genetic control early in development but may be affected by environmental factors during first trimester of pregnancy. These patterns may represent the genetic make up of an individual and therefore his/her predisposition to certain diseases. The finger and palmar print patterns have already beenstudied with respect to various genetic diseases such as the Down's syndrome and Klinefeltersyndrome. The fingerprints can thus represent a simple, noninvasive anatomical marker of breast cancer risk.

Methods :This study was applied to fifty histopathologically-confirmed breast cancer patients and their fingerprints patterns were assessed. At the same time, fifty age-matched controls were selected being have no self or family history of breast cancer and the observations were recorded abd data were collected.

Result :It was observed that whorl pattern is the most common fingerprints pattern to be identified in breast cancer cases compared to controls. Also the quantitative difference in ridge count was statistically important.

Conclusion : The pattern of fingerprints may be a useful tool in the future in identifying and also screening of breast cancer.

Key Words : Breast cancer, Fingerprints, Genetics, Screening

| E-mail: alaaahmedhagag@gmail.com, 00201062685503

\section{INTRODUCTION}

B reast cancer is defined as the uncontrolled growth of abnormal cells in the milk producing glands of the breast or in the passages (ducts) that deliver milk to the nipples.Each year more than one million women are diagnosed with breast cancer worldwide over half of whom die from the disease.(1).Breast cancer is the most frequently diagnosed life-threatening cancer in women(2). The genetic component in breast cancer is well established and various genes like (BRCA1 and BRCA2), p-53 etc. have been extensively studied and identified as genetic links $(\mathbf{3 , 4 , 5})$. Breast cancer could be screened using soft tissue mammography, breast ultrasound and magnetic resonance imaging (14) Studies are available suggesting that a family history of breast cancer might be associated with a specific fingerprint pattern (610). Fingerprint determination is genetic but has been reported to be affected by the environmental factors in the first trimester of pregnancy. After birth the patterns remain more or less constant and hence may serve to study the genetic patterns in any individual (11). The fingerprints could thus be used for screening or to guide future research in this direction which can be used an simple non-ivnasive method for screening breast cancer.the finger prints of each individual are unique and even identical twins have different fingerprints pattern (11).

Method :This study includes 100 patients, divided into two groups (A \& B). Group A includes 50 patients were histopathologically confirmed that they have breast cancer and Group B includes 50 patients were breast cancer free, they have no self or family history of breast cancer. After informed consent, the fingerprints pattern of both groups were collected using paper and ink method, patterns were identified and ridges were counted by 
Z.U.M.J.Vol. 24; No.1 Jan.;2018

Forensic medicine consultant.There are five patterns of fingerprints which are (Whorls, Radial Loop, Ulnar Loop,Arches and Compound) .The results were tabulated The study was done in Zagazig University Hospitals.

Results :The fingerprints pattern were identified and tabulated for both breast cancer
Study of Fingerprints Pattern in Breast......

patients and controls.It was commonly observed that the whorl pattern increased significantly in cases compared to controls in both right and left hands, being $48 \%$ of total patterns in right hand of cases compared to controls which was $24 \%$, and $48 \%$ in left hand compared to control which was 26\%(Tables 1,2,3,4).

(Table 1) Fingerprints Pattern in the Right Hand of 50 Controls

Commonest Pattern identified

Number of Cases

Percentage

\begin{tabular}{ccc}
\hline Whorl & 12 & $24 \%$ \\
Radial Loop & 30 & $60 \%$ \\
Arch & 4 & $8 \%$ \\
Ulnar Loop & 2 & $4 \%$ \\
Compound & 2 & $4 \%$ \\
Total $=\mathbf{5 0}$ & $\mathbf{1 0 0} \%$ & \\
\hline
\end{tabular}

$\underline{\text { Table(2) fingerprints pattern in } 50 \text { breast cancer cases }}$

Commonest Pattern Identified $\quad$ Number of patients $\quad$ Percentage

\begin{tabular}{ccc}
\hline Whorl & 23 & $46 \%$ \\
\hline Radial Loop & 21 & $42 \%$ \\
Arch & 2 & $4 \%$ \\
\hline Ulnar Loop & 3 & $6 \%$ \\
Compound & 1 & $2 \%$ \\
\hline Total $=50$ & & $100 \%$ \\
\hline
\end{tabular}


Table (3) :Fingerprints Pattern in Left Hand of 50 Cases of Breast Cancer

Commonest Pattern identified

Percentage

\begin{tabular}{ccc}
\hline Whorl & $\mathbf{2 4}$ & $\mathbf{4 8} \%$ \\
Radial Loop & $\mathbf{2 1}$ & $\mathbf{4 2} \%$ \\
Arch & $\mathbf{2}$ & $\mathbf{4 \%}$ \\
Ulnar Loop & $\mathbf{2}$ & $\mathbf{4 \%}$ \\
Compound & $\mathbf{2} \%$ \\
Total & $\mathbf{5 0}$ & $\mathbf{1 0 0} \%$ \\
\hline
\end{tabular}

Table (4) :Fingerprints Pattern in Left Hand of 50 of Control Group

Commonest Pattern Identified Number of cases Percentage

\begin{tabular}{ccc}
\hline Whorl & $\mathbf{1 1}$ & $\mathbf{2 2} \%$ \\
\hline Radial Loop & $\mathbf{2 7}$ & $\mathbf{5 4} \%$ \\
Arch & $\mathbf{7}$ & $\mathbf{1 4 \%}$ \\
\hline Ulnar Loop & $\mathbf{2}$ & $\mathbf{4 \%}$ \\
\hline Compound & $\mathbf{3}$ & $\mathbf{6 \%}$ \\
\hline Total & $\mathbf{5 0}$ & $\mathbf{1 0 0} \%$ \\
\hline
\end{tabular}

Also, the mean ridge count was calculated in all digits in both hands . The mean ridge count in right hand of cases was 9.78 and 15.16 in controls.the mean ridge count in left hand of cases was 10.92 and 15 in controls. (Tables 5,6,7,8). 
(Table 5) Ridge count in Right Hand of 50 Breast Cancer Patients

Digit Total ridge count Mean Ridge count

\begin{tabular}{ccc}
\hline Thumb & 705 & 14.1 \\
Index & 505 & 10.1 \\
Middle & 410 & 8.2 \\
Ring & 430 & 8.6 \\
Little & 400 & 8 \\
\hline
\end{tabular}

Mean Ridge Count in cases in right hand $=9.78$

(Table 6) Ridge Count in Right hand of 50 Controls

\begin{tabular}{ccc}
\hline Digit & Total ridge count & Mean ridge count \\
\hline Thumb & 975 & 19.5 \\
\hline Index & 675 & 13.5 \\
Middle & 610 & 12.2 \\
Ring & 820 & 16.4 \\
\hline Little & 710 & 14.2 \\
\hline
\end{tabular}

Mean ridge count in right hand of controls $=15.16$

(Table 7) Ridge count in Left Hand of 50 Breast Cancer Patients

Digit Total ridge count Mean Ridge Count

\begin{tabular}{ccc}
\hline Thumb & 630 & 12.6 \\
Index & 440 & 8.8 \\
Middle & 565 & 11.3 \\
Ring & 625 & 12.5 \\
Little & 470 & 9.4 \\
\hline
\end{tabular}

Mean ridge count in Left hand of cases $=10.92$ 
(Table 8) Ridge count in Left Hand of 50 Controls

Digit Total ridge Count

Mean Ridge Count

\begin{tabular}{ccc}
\hline Thumb & 1025 & 20.5 \\
Index & 710 & 14.2 \\
Middle & 530 & 10.6 \\
Ring & 705 & 14.1 \\
Little & 800 & 16 \\
\hline
\end{tabular}

Mean Ridge Count in Left Hand of Controls $=15$

\section{DISCUSSION}

Breast cancer accounts for $29 \%$ of all cancers in women and is second only to lung cancer as a cause of cancer deaths in United States (12).

Breast cancer is defined as the uncontrolled growth of abnormal cells in the milk producing glands of the breast or in the passages (ducts) that deliver milk to the nipples.Each year more than one million women are diagnosed with breast cancer worldwide over half of whom die from the disease (1).

In some studies a pattern of six or more digital whorls was recorded more frequently in women with breast cance than in those without the disease $(\mathbf{1 1}, \mathbf{1 3})$. The presence of six or more whorls was found to be significant as noted by $32.4 \%$ of breast cancer patients possessing this number of whorls as compared to $3.1 \%$ controls. Also of note is that $95 \%$ of subjects with six or more whorls either had cancer or were at high-risk. Similar results were obtained in the present study. Loops, arches and whorls are the common patterns observed in individuals.

Presence of Whorl pattern in the present study is also important for a different reason. It is seen that the whorl pattern frequency showed maximal changes as compared to other patterns i.e. $4 \%$ increase in the right digits in cancer patients as compared to controls.

Aslo. The mean ridge count was of statistical significance. It is showen that the mean ridge count in the right hand was less than that of controls, it could be used as a significant observation.

This relatively non-invasive technique can reasonably be used in selective nonsymptomatic women (those with positive family history) as a part of definite risk assessment strategy with an ability to detect the earliest changes associated with developing cancer many years before the appearance of clinically assessed tumor and this may allow the introduction of more effective chemopreventive measures and early diagnosis and treatment in patients with breast cancer.

\section{CONCLUSION}

In conclusion, among fifty patients diagnosed as carcinoma breast patients, the whorl pattern was the most common fingerprints pattern to be repeated among these patients. Patients with breast cancer often have six or more whorls in their finger tips.

In the future, fingerprints can be a very simple,easy, non expensive and non invasive method for screening breast cancer.

Women who at high risk to have breast cancer can seek help of specialized centers to 
examine their fingerprints pattern and take the prophylactic measures as early as possible.

\section{REFERENCES}

1-Garcia $M$ et al. Global Cancer Facts \& Figures. Atlanta, GA: American Cancer Society, 2007.

2-Torre LA, Bray F, Siegel RL, Ferlay J, LortetTieulent J, Jemal A. Global cancer statistics, 2012. CA Cancer J Clin. 2015 Mar. 65(2):87-108.

3- Saxena S, Rekhi B, Bansal A, Bagga A, Chintamani , Murthy NS: Clinico- morphological patterns of breast cancer including family history in a New Delhi hospital, India - a cross-sectional study. World $J$ SurgOncol3:67. 2005 Oct 13.

4- Chintamani, Singh JP, Mittal MK, Saxena S, Bansal A, Bhatia A: Role of p-glycoprotein expression in predicting response to neoadjuvantchemotherapy in breast cancer - a prospective clinical study. World J SurgOncol3:61. 2005 Sep 14Bhatnagar.

5- Saxena S, Chakraborty A, KaushalM, Kotwal S, Bhatnagar D, MohilRS, Chintamani , Agarwal AK, Sharma VK, Sharma PC, Lenoir G, Goldgar DE, Szabo CI: Contribution of germline BRCA1 andBRCA2 sequence alterations to breast cancer in NorthernIndia. BMC Med Genet 7:75. 2006 Oct 4.

6- Gilligan SB, Borecki IB, Mathew S, Malhotra KC, Rao DC:A familystudy of dermatoglyphic traits in India: A search for majorgene effects on palmar pattern ridge counts. Am J PhysAnthropol1985, 68(3):409-16.
7-Kobyliansky E, Bejerano M, Yakovenko K, Katznelson M:Relationshipbetween Genetic Anomalies of Different Levels andDeviations in DermatoglyphicTraits. Part IV: Dermatoglyphicpeculiarities of males and females with Down Syndrome.Family Study. AnthropAnz1999, 57(3):193-255.

8-Bierman HR, Faith MR, Stewart ME: Digital dermatoglyphics in mammary cancer. Cancer Invest 1988, 6(1):15-27.

9-Lynch HT, Albano WA, Heieck JJ, Mulcahy GM, Lynch JF, Layton MA,Danes BS: A review. Genetics, biomarkers, and control ofbreast cancer. Cancer Genet Cytogenet1984, 13(1):43-92.

10- Lynch HT: Genetics and Breast Cancer. New York. Van NostrandReinhold Company; 1981.

11- Seltzer Murray H, Plato Chris C, Kathleen Fox M: Dermatoglyphicsin identification of Women Either with or at risk for breast cancer. American Journal of Medical Genetics 1990, 37:482-488.

12-Siegel RL, Miller KD, Jemal A. Cancer Statistics, 2017. CA Cancer J Clin. 2017 Jan. 67.

13. Abbasi S, Einollahi N, Vaez-Zadeh F: Study of dermatoglyphicPatterns of Hands in

Women with Breast cancer. Pak J MedSci2006, 22:1822.

14. Crystal P, Strano SD, Shcharynski S, et al. Using sonography to screen women with mammographically dense breasts. Am J Roentgenol. 2003;181:177-82. 